\title{
Prehistoric archaeology
}

\section{Martin Rudwick}

Men among the Mammoths: Victorian Science and the Discovery of Human Prehistory. By A. Bowdoin Van Riper. University of Chicago Press: 1993. Pp. 267. \$51.75, £35.95 (hbk); \$19.50, $£ 13.50$ (pbk).

THE year 1859 was an annus mirabilis in two distinct areas of science, a date almost worthy of 1066 and All That. The appearance of Darwin's Origin of Species showed publicly that a reputable naturalist had joined what had previously been the scientifically suspect side of the long-running debate about organic evolution. But the heightening of that debate, with its implications for human self-understanding, tends to overshadow events of equal significance a few months earlier, when a series of addresses given by certain leading geologists to some of the most respected scientific bodies in Britain presented a tightly argued case for concluding that early human beings had coexisted with the extinct mammals of the Pleistocene period. Men among the Mammoths is a highly readable account of the research that expanded the scale of antiquity for the human species, and integrated human history into the far longer narrative of Earth history.

This was indeed, a "great and sudden revolution", as one contemporary called it. In little more than 18 months a long-standing but dubious speculation was tranformed into a solid con-

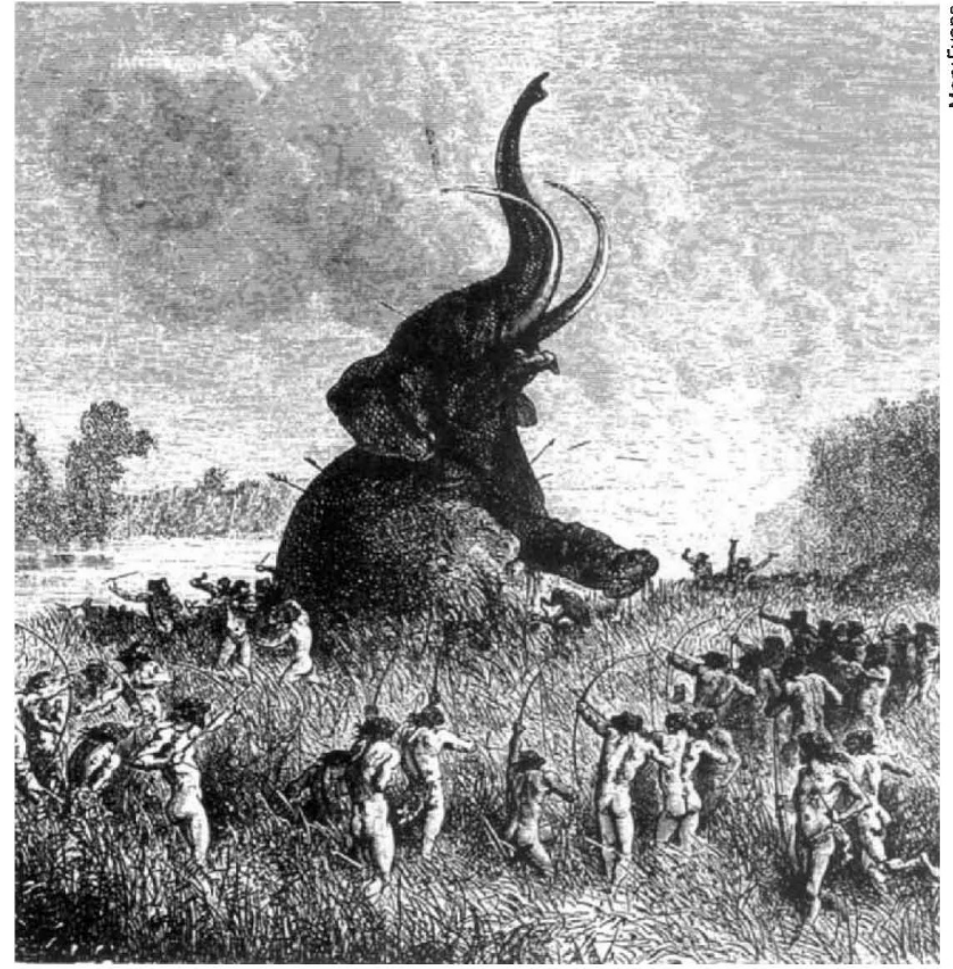

Mammoth among the men - new evidence found in the early nineteenth century greatly strengthened the case for the coexistence of man and extinct animals. saw little reason to concern themselves with crude stone artefacts that were unconnected with any such sites, and might not even be of human workmanship. Among geologists, on the other hand, there had already been decades of debate about alleged mixtures of human and animal remains in the geologically recent deposits of the 'Drift' (or 'Post-Pliocene') period. In particular, the pitfalls of interpretation surrounding deposits in caves in which most such mixtures had been found - were well recognized.

The evidence that precipitated the 'revolution' came first from the newly discovered Brixham cave in Devon: excavated with unprecedented care, this greatly strengthened the case for the contemporaneity of human beings and extinct mammals. That case was then swiftly clinched,

experts; and he shows how a new discipline of "prehistoric archaeology" was built on the territory of the "Old Stone Age" or Palaeolithic period. The contemporaneity of early human beings and extinct mammals, and the vastly enlarged scale of human antiquity that was its corollary (not uncontested), carried implications for man's place in nature that were as far-reaching as those of Darwin's Origin. Van Riper shows, however, that there was no simplistic conflict of 'science versus religion' on this issue, but a wide range of responses: for example, the new biblical criticism exemplified in the famous volume Essays and Reviews (published coincidentally at just this time) was quite as influential as any backwoods literalism. As for the rise of a newly defined discipline, Van Riper shows how the proponents of "prehistoric archaeology" captured and transformed the older institutions so successfully that the study of pre-literate cultures, exploiting the methods of both geology and anthropology, became virtually synonymous with archaeology itself, banishing the earlier discipline to the sidelines.

Van Riper's story is almost entirely a British one, and he defends that perspective on the grounds that it reflects the cutting edge of the historical case for human antiquity. That is at least partly true. But a parallel debate of equal intensity was agitating Parisian savants at that time; after all, much of the ultimately decisive evidence was found on French soil. Van Riper acknowledges this in passing, for example when he deals with the celebrated case of the allegedly fraudulent MoulinQuignon jaw (a forerunner of the Piltdown one, as it sensus, at least among the scientists most competent to judge the evidence. Van Riper, however, rightly sets that exciting period into a longer and richer historical and scientific context. He shows, first, why the context of the new discoveries was geological rather than archaeological. In the early nineteenth century, archaeologists were mainly concerned with supplementing the documentary record of the periods of literate history (Van Riper calls them "historical" archaeologists). Their interests, often local in character, centred on the Middle Ages, and faded out when traced back beyond Roman times into the shadowy pre-literate 'Celtic' period of 'monuments' such as Stonehenge. They

to the satisfaction of almost all the scientists involved, by finds confirming earlier claims that similar stone tools in the ancient gravels of the Somme were truly associated with the bones of extinct animals; for these gravels were regarded as much less problematic deposits than those in any cave. Van Riper's narrative of these events is the core of his book; it is a fascinating story that is sensitive to the tensions between the London élite and the local amateurs of Torquay and Abbeville, and to the social dynamics among the élite scientists themselves.

To round off, Van Riper traces the varied responses of wider groups in British society to the new conclusions of the were). More on the international dimension would have made his account still better. As it is, a tale of two cities is almost reduced to a tale of one; but it is nonetheless a tale finely told. Indeed, this book is a rarity: although it started life as a dissertation, it is beautifully written, in prose that is elegant yet simple and lucid, and it is a pleasure to read. Its highly visual subject matter deserved many more illustrations, but the book itself is produced to high standards.

Martin Rudwick teaches the history of science in the Science Studies Program at the University of California, San Diego, La Jolla, California 92093-0104, USA. 